\title{
Use Your Head! Exploring Interaction Modalities for Hat Technologies
}

\author{
Christine Dierk \\ University of California, Berkeley \\ Berkeley, CA, USA \\ cdierk@berkeley.edu
}

\author{
Scott Carter, Patrick Chiu, Tony Dunnigan, Don Kimber \\ FX Palo Alto Laboratory, Inc. \\ Palo Alto, CA, USA \\ \{carter, chiu, tonyd, kimber\}@fxpal.com
}
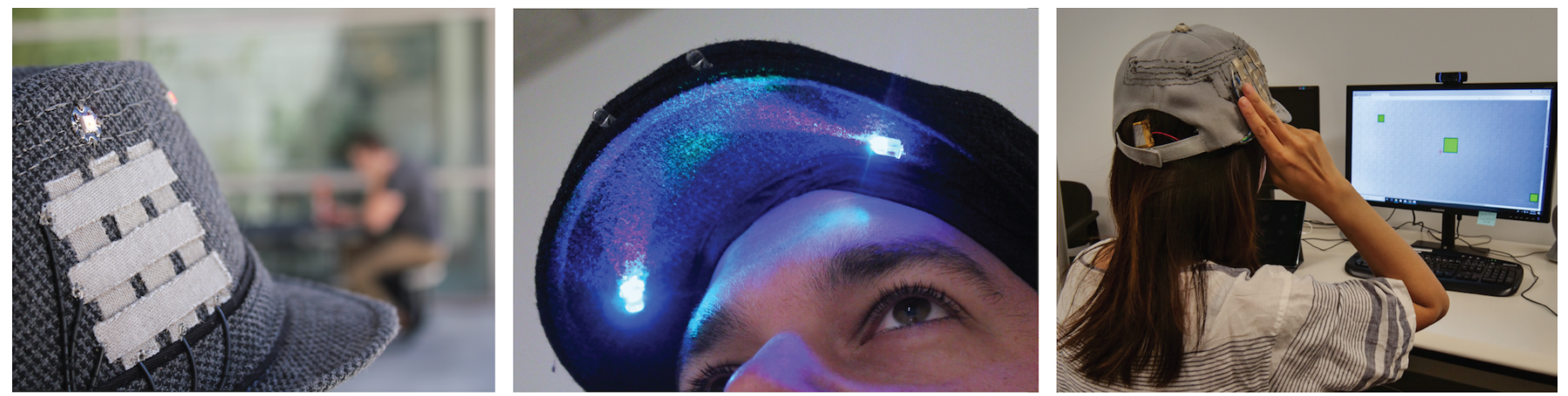

Figure 1. Left: touch sensitive region and public crown display of the fedora prototype. Middle: personal under-brim display of the flap cap prototype. Right: user evaluation of our baseball cap prototype.

\begin{abstract}
As our landscape of wearable technologies proliferates, we find more devices situated on our heads. However, many challenges hinder them from widespread adoption — from their awkward, bulky form factor (today's AR and VR goggles) to their socially stigmatized designs (Google Glass) and a lack of a well-developed head-based interaction design language. In this paper, we explore a socially acceptable, large, head-worn interactive wearable - a hat. We report results from a gesture elicitation study with 17 participants, extract a taxonomy of gestures, and define a set of design concerns for interactive hats. Through this lens, we detail the design and fabrication of three hat prototypes capable of sensing touch, head movements, and gestures, and including ambient displays of several types. Finally, we report an evaluation of our hat prototype and insights to inform the design of future hat technologies.
\end{abstract}

\section{CCS Concepts}

-Human-centered computing $\rightarrow$ Human computer interaction (HCI);

\section{Author Keywords}

wearables; elicitation study; user-defined gestures; ambient displays; hats; headwear.

Permission to make digital or hard copies of all or part of this work for personal or classroom use is granted without fee provided that copies are not made or distributed for profit or commercial advantage and that copies bear this notice and the full citation on the first page. Copyrights for components of this work owned by others than the author(s) must be honored. Abstracting with credit is permitted. To copy otherwise, or republish, to post on servers or to redistribute to lists, requires prior specific permission and/or a fee. Request permissions from Permissions@ acm.org.

DIS '19, June 23-28, 2019, San Diego, CA, USA

(C) 2019 Copyright is held by the owner/author(s). Publication rights licensed to ACM. ACM 978-1-4503-5850-7/19/06 \$15.00

https://doi.org/10.1145/3322276.3322356

\section{INTRODUCTION}

An increasing number of wearable devices are situated on our heads - from traditional heads-up displays [36, 44] and AR/VR headsets to interactive jewelry [20,33], makeups [11, $13,41,39]$, and even hair [8, 40]. These wearable interfaces can be separated into two distinct groups: technologies that introduce new form factors and technologies that leverage existing ones. Leveraging a familiar form factor can alleviate concerns of social acceptability and lead to faster adoption. Additionally, established form factors come with a rich history of past use and cultural meaning. This provides a unique opportunity to design wearable technologies that reflect these practices. In this paper, we explore the interaction capabilities of a well established head-worn form factor - hats.

Hats exist in nearly all cultures throughout the world, reflecting rich traditions over generations and acting as an extension of self [5]. Hats are diverse, and the form of the hat conveys information about the wearer. Surgical caps, bicycle helmets, yarmulkes, ushankas, and fedoras are all worn in different contexts and have different inherent functions: providing protection, restraining hair, communicating religious beliefs, or attesting to personal style. This diversity of hats provides an exciting opportunity to marry function and form through the design and creation of hat technology.

This paper discusses the design, implementation, and evaluation of hat technology. We first outline 5 design concerns for interactive hats. Next, we report results from a gesture elicitation study aimed at identifying appropriate input modalities, and extract a taxonomy of hat-based gestures. As an exemplar of how the design concerns and taxonomy can be used in practice, we discuss the implementation of three interactive hat prototypes and conduct a preliminary evaluation. Finally, we discuss implications for the design of future hat technologies. 


\section{RELATED WORK}

We briefly outline related hat-based interfaces and headmounted gestural interfaces, focusing specifically on afforded interaction modalities.

Hat-Based Interfaces: Researchers and companies alike have begun to explore the vast potential for hats and other headwear as a location for technology. Prior work has embedded visual displays and sensors into hats as a means of personal expression [7], light therapy [27], EEG monitoring ${ }^{1}$, and mobile device control [35]. Additionally, a number of smart helmets have been designed to increase spatial awareness and visibility of cyclists [30,42]. Prior work has also begun to examine how hats can be used as input devices. Strohmeier et al. implemented hover and touch gestures on the crown of a beanie [35]. Mistry et al. mounted a camera to a baseball cap to characterize in-air gestures [22]. However, neither of these works justify or contextualize the choice of a hat form factor. In fact, future iterations of the work by Mistry et al. abandoned the hat completely, instead opting for a pendant form factor [21].

Head-Mounted Gestural Interfaces: While some headmounted gestural interfaces have assumed a hat form factor [22], many more have taken other forms such as glasses (Google Glass), headsets (Microsoft Hololens), and beyond [14]. These interfaces utilize eye tracking [31], in-air gestures [22], head gestures [45], voice commands, touch gestures, neuromuscular signals [14], or a combination of the above. For example, Microsoft HoloLens ${ }^{2}$ uses a combination of gaze, voice, and in-air gestures. Alternatively, Google Glass ${ }^{3}$ incorporates a suite of voice commands, head gestures, and touch gestures. In this paper, we attempt to provide a grounded taxonomy for future designers to use in navigating potential input modalities.

\section{DESIGN CONCERNS FOR INTERACTIVE HATS}

Hats cover a unique design space; they have different limitations and opportunities than other wearable devices, even those worn on the head. Hats combine the larger surface area of VR headsets with the casual everydayness of eyeglasses. Like hair, they can communicate personal style, but are trivially changeable. Furthermore, hats span a wide set of design concerns. They can in some contexts communicate deeply personal beliefs (e.g, at a religious ceremony) while in other contexts they can be purely utilitarian (e.g., at a construction site) or some combination of both (e.g., outdoor activities). While they are generally designed to be touched and rearranged, in some ceremonial contexts excessive touching may represent a faux pas.

The extensive design space for hats makes it particularly difficult to generate a set of unifying design recommendations for interactive hats. Our approach, therefore, is to first describe broad design concerns and then explain how designers can reify these concerns in particular designs. To arrive at these concerns, we surveyed relevant literature on wearable devices, and applied considerations to our hat form factor.

\footnotetext{
${ }^{1}$ http://www.smartcaptech.com/life-smart-cap/

${ }^{2}$ https://www.microsoft.com/en-us/hololens

${ }^{3}$ https://www.X.company/glass/
}

\section{Design Concerns}

\section{Information Legibility}

A key aspect of many wearable devices is the ability to communicate with the wearer. This communication is vital for notifications, feedback, and applications, and is often vibrotactile, aural, or visual in nature. We discuss each of these modalities in relation to our hat form factor.

(a) Vibrotactile. Hats tend to closely fit the wearer's head, and thus do not provide many opportunities for vibrotactile communication. Rather than eliciting a physical sensation, vibration is conducted through the bones of the skull to the inner ear, and the wearer hears a buzzing sound. However, vibration may prove effective for certain types of hats with loose-fitting features, such as lanyards, ear flaps, or tassels. Additionally, designers can leverage the buzzing from vibration motors as a mode of aural communication.

(b) Aural. While the close-fitting nature of hats limits haptic feedback, it enables bone conduction. Hats provide a privileged location for technology of this type, as evidenced in Kickstarter campaigns ${ }^{4}$ and prior work [30].

(c) Visual. Hats also provide unique opportunities for visual communication. Most hats include a brim, typically to shield the wearer's eyes from the sun. This portion of the hat is always visible in the wearer's peripheral vision, and thus provides a platform to mount peripheral displays. However, these displays are close to the wearer's eyes and could easily become overly distracting. Therefore, designers of hat technologies should take care to ensure that under-brim displays are low-fidelity and ambient [18].

Hats provide a host of potential low-fidelity modes of communication. Designers of hat technologies should consider the trade-offs between these modalities with regards to their particular domains.

\section{Privacy}

In addition to communicating with the wearer, wearable devices often have a means to communicate with onlookers, frequently using visual changes to convey personal style [12, $7]$, emotional state $[17,10]$, and other types of information $[25,11,41,34]$. Such public information is well suited for the crown: a prominent and visible portion of the hat. However, every attempt should be made to make sure the wearer is aware of the information the hat is broadcasting, especially if it is personal in nature. Additionally, prior work indicates that wearers are more comfortable displaying personal information when it is abstract, ambient, and ambiguous [6, 9, 10].

Hats must carefully consider privacy concerns, particularly with regards to displayed information.

\section{Interaction Legibility}

Wearable devices often provide visual or tactile indications of their interactive affordances. The Levi's ${ }^{\circledR}$ Commuter $\mathrm{X}$ Jacquard By Google trucker jacket ${ }^{5}$ includes visible threads in the interactive cuff; Nenya, a magnetically tracked ring for mobile device input, uses an attached disc magnet as a tactile

\footnotetext{
${ }^{4}$ https://www.kickstarter.com/projects/781010162/cap-on-sound-on ${ }^{5}$ http://www.levistrauss.com/unzipped-blog/2017/09/25/leviscommuter-trucker-jacket-jacquard-google/
} 
means to inform interaction [2]; physical buttons on the side of smartwatches and activity monitors provide both visual and tactile cues. In addition to increasing Discoverability [24], these cues can provide feedback for input gestures. Hats are distinct in that wearers typically cannot see the surface they are interacting with; thus, tactile indications of interactive capabilities are paramount.

Tangible landmarks provide tactile feedback and can serve as a natural place to situate interactions. Buttons and eyelets can map to discrete state selection events, while brims and lanyards can be augmented to provide continuous input.

\section{Context of use}

Wearable devices often sense user activity and tailor interactions accordingly. For instance, activity monitors have different functions during periods of activity and periods of rest. These devices often discern user activity using readings from embedded sensors, or communicating with external systems (e.g., smartphones, smartwatches, smart environments). Interactive hats may also have embedded sensors or access to these external systems; however, the form of the hat itself can also indicate user activity (e.g., bicycle helmets, surgical caps, and fedoras are all worn in very different contexts). Hat technologies should use these contexts to enact different features. For example, if a smart hardhat detects a slow ascent or descent in relative darkness, it might enable features related to climbing or spelunking. Conversely, a smart top hat may use the same sensor readings to delineate acts of a play, enabling different modes for show-time and intermission.

Interactive hats should use context to enact different features. Designers should consider available sensors and external systems, as well as the context of the hat itself.

\section{Aesthetics and inherent functions}

Many wearable devices assume existing form factors that have functions of their own. We refer to these as inherent functions. At their core, smartwatches are watches and thus need to be able to communicate time. Wearables in the form of clothing, accessories, and cosmetics are articles of personal fashion, and must fit within the wearers' sense of style. Interactive hats must also consider inherent functions. Hats serve a variety of purposes, and it is critical that interactive hat designers preserve them if they are valuable to the wearer. Hats can provide shelter from the sun, wind, insects, or other external sources; they can protect the head from sharp blows or pressurization; and they can communicate personal style or beliefs.

Interactive hats must carefully consider aesthetics and inherent functions. Electronics should be concealed where feasible, and the visual appearance and structural integrity of the hat should be preserved as much as possible.

\section{Embodiment of Design Concerns}

Design concerns and recommendations are only useful if they can be enacted in real designs. To accomplish this goal, we conducted a gesture elicitation study to develop a taxonomy of hat-based gestures; we then apply this taxonomy through the lens of our design concerns to implement interactive gestures and displays on three hat styles. We describe a second study

\begin{tabular}{|c|c|c|c|}
\hline Category & Referent & Category & Referent \\
\hline \multirow{8}{*}{ Navigation } & Previous & \multirow{8}{*}{ Simulation } & Answer Call \\
\hline & Next & & Hang Up Call \\
\hline & Pan Left & & Dismiss Notification \\
\hline & Pan Right & & Volume Up \\
\hline & Pan Up & & Volume Down \\
\hline & Pan Down & & Play \\
\hline & Zoom In & & Pause \\
\hline & Zoom Out & & Stop \\
\hline \multirow{8}{*}{ Editing } & Cut & \multirow{5}{*}{ Мепи } & Help \\
\hline & Copy & & Open Menu \\
\hline & Paste & & Close Menu \\
\hline & Delete & & On \\
\hline & Accept & & Off \\
\hline & Reject & \multirow{3}{*}{ Selection } & Select Single \\
\hline & Undo & & Select Multiple \\
\hline & Save & & Select All \\
\hline
\end{tabular}

Table 1. The list of referents presented to participants grouped by category. Five gestures were repeated under additional conditions (See Table 3); these are shown in pink italic.

we conducted to explore our gesture taxonomy and hat display techniques with users. Finally, we offer a broader discussion of how designers can use our gesture taxonomy and design concerns to inform the design of other interactive hats with different styles and contexts-of-use.

\section{USER-DEFINED GESTURES FOR HAT TECHNOLOGY}

We conducted a gesture elicitation study with 17 participants to inform interactions with hat technologies. The purpose of this study was to identify appropriate inputs to hat-worn technology and to inform the design and fabrication of future prototypes.

\section{Elicitation Studies for Gesture Design}

Gesture elicitation studies are well established in the field of HCI [43, 32, 3, 28, 16, 1, 15, 4, 38, 26]. Gesture elicitation is a technique in which users are given the result of an action (called a referent) and asked to propose a gesture (called a symbol) that would cause that result [43]. Kim et al. [15] conducted a gesture elicitation study with a variety of wearable objects as input to a small audio device. One of the objects they evaluated was a baseball cap. We contextualize this Work-InProgress by eliciting gestures for a wider variety of referents, extracting a taxonomy, and building prototypes capable of detecting elicited gestures.

\section{Study Design}

Selection of Referents: We wanted to form a broad list of common tasks to generalize gestures across a wide range of applications. To acheive this, we first looked at the referents used by Wobbrock et al. [43]. We removed referents that were heavily dependent on external visualizations (e.g., "Rotate", "Insert"). We also removed referents that were similar in nature; in our study's context, "Shrink", "Minimize", and "Zoom Out" can all be encapsulated by "Zoom Out". We then added several referents specific to phones and wearable devices (e.g., "Answer Call", "Dismiss Notification", "Volume Up", etc), as well as panning gestures. We then grouped referents in five of the six categories used in both Chan et al.'s elicitation study for single-hand microgestures [4] and Piumsomboon et al.'s elicitation study for augmented reality [26] (none of our remaining referents fell under their "Transform" category). Finally, we renamed the "Browsing" category "Navigation", 


\begin{tabular}{|l|l|}
\hline & Gesture Statements \\
\hline G1 & The gesture I picked is a good match for its intended use. \\
\hline G2 & The gesture I picked is easy to perform. \\
\hline G3 & The gesture I picked is easy to remember. \\
\hline & Hat Statements \\
\hline H1 & Interaction with a smart hat is natural. \\
\hline H2 & I would prefer to interact with a smart hat over a mobile device. \\
\hline H3 & I would prefer to interact with a smart hat over a smartwatch. \\
\hline H4 & I would feel comfortable interacting with a smart hat in public. \\
\hline
\end{tabular}

Table 2. Participants in both user studies were asked to rate each individual gesture on the above gesture statements. At the conclusion of each study, participants were asked to rate the hat more generally on the above hat statements. All statements in both studies used a 7-point Likert scale.

to better suit our wearable context. Thus, we have a total of 32 referents clustered into 5 categories: Navigation, Editing, Simulation, Menu, and Selection (See Table 1).

Selection of Hat: We conducted our study using a plain baseball cap (See Figure 2). We chose this type of hat because they are relatively ubiquitous in the Western society in which this study took place.

“Infinite Technology": Participants were explicitly instructed not to think about

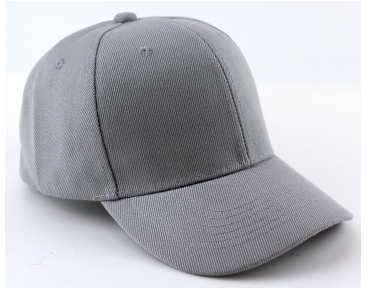

Figure 2. The baseball cap used in our study. technical implementation and assume that any conceivable gesture would be recognized.

Legacy Bias: We took several measures to reduce legacy bias. Legacy bias occurs when participants' gesture proposals are biased by their experience with prior interfaces, interaction paradigms, and technologies [23]. We applied two techniques to reduce legacy bias: priming and production [23]. We applied priming by asking participants to imagine two additional conditions: that their hands were dirty but mobile, and that their hands were preoccupied and immobile (See Table 3). We applied production by asking participants to propose two gestures for each referent.

Additional Conditions: Participants were asked to repeat 5 referents (Table 1, pink italic) under two additional conditions: Hands Dirty and Hands Preoccupied (Table 3). These conditions were chosen to highlight advantages of hat-worn technology, namely that it can support hands-free interaction with personal and public devices alike.

Using hat interactions, a cook could pause music that they are listening to, have a conversation on their smart phone, and then resume listening to their music without contaminating food they are preparing. An engineer could zoom in on a circuit diagram without putting down their soldering iron and losing their place on the PCB.

\section{Participants}

We conducted our elicitation study with 17 participants (15 male, 2 female). Participants were recruited using email lists and word of mouth. The participants ranged in age from 18 to 65 (Mean $=37.5, \mathrm{SD}=13.2$ ). Fifteen participants were right handed, one left handed, and one ambidextrous. All

\begin{tabular}{|c|l|}
\hline Condition & Explanation to Participants \\
\hline $\begin{array}{c}\text { Hands } \\
\text { Dirty }\end{array}$ & $\begin{array}{l}\text { Imagine your hands are dirty. Perhaps you are } \\
\text { cooking or changing the oil in your car. You can } \\
\text { move your hands around, but you do not want } \\
\text { to physically touch the hat. }\end{array}$ \\
\hline $\begin{array}{c}\text { Hands } \\
\text { Preoccupied }\end{array}$ & $\begin{array}{l}\text { Imagine your hands are full. Perhaps you are } \\
\text { soldering or carrying a bunch of items. You } \\
\text { cannot move your hands. }\end{array}$ \\
\hline
\end{tabular}

Table 3. After participants had completed the 32 gestures, they repeated 5 of those gestures under two additional conditions: hand dirty and hands preoccupied.

participants owned smartphones and laptops and rated themselves as using them on a daily basis. Thirteen participants owned tablets; 8 participants owned a smartwatch. While not a requirement for participation, all participants owned at least one type of hat, and ranged from wearing them daily to rarely ("several days in the winter" or "only in summer"). The study took around 45 minutes to complete.

\section{Procedure}

We first gathered background experience with headwear and technology. We collected this information to contextualize results, particularly with respect to legacy bias. Participants were then given a plain gray baseball cap (Figure 2) to wear during the study. Participants were instructed to wear the hat as they normally would. Only 1 participant chose to wear the hat "backwards"; all other participants wore the hat with the brim in the front (As in Figure 8).

We presented a total of 32 referents, broken up into 5 categories based on function (See Table 1). We verbally described the resulting effect (referent) and asked participants to design and perform an input gesture (symbol). Participants were asked to design two gestures for each referent, before identifying which they preferred. After the participants had decided upon a gesture, the participants were asked to rate the gesture using a 7-point Likert scale on 3 statements (See "Gesture Statements" in Table 2). Referents were always presented in the same order. Participants were allowed to repeat a single gesture for multiple referents, if desired.

After completing the 32 referents, the participants were asked to repeat 5 of the referents (Table 1, pink italic) under two additional conditions: Hands Dirty and Hands Preoccupied (Table 3 ). Inspired by the conceptual complexity ratings utilized in [43], these tasks were chosen to cover a range of category types and complexities.

The study concluded with an assessment questionnaire. Participants were asked to rate the interactions more generally using a 7-point Likert scale on 4 statements (See "Hat Statements" in Table 2). All interview meetings were video and audio recorded, transcribed, and analyzed using grounded theory. In total, each participant was presented with 42 tasks (32 initial tasks $+(5$ representative tasks $\times 2$ conditions $))$.

\section{Analysis}

With 17 participants, 1,428 gestures were made, collected, and analyzed (17 participants x 42 tasks x 2 gestures). The data collected includes transcripts, videos, preliminary questionnaires, and gesture \& hat rankings (Table 2). 


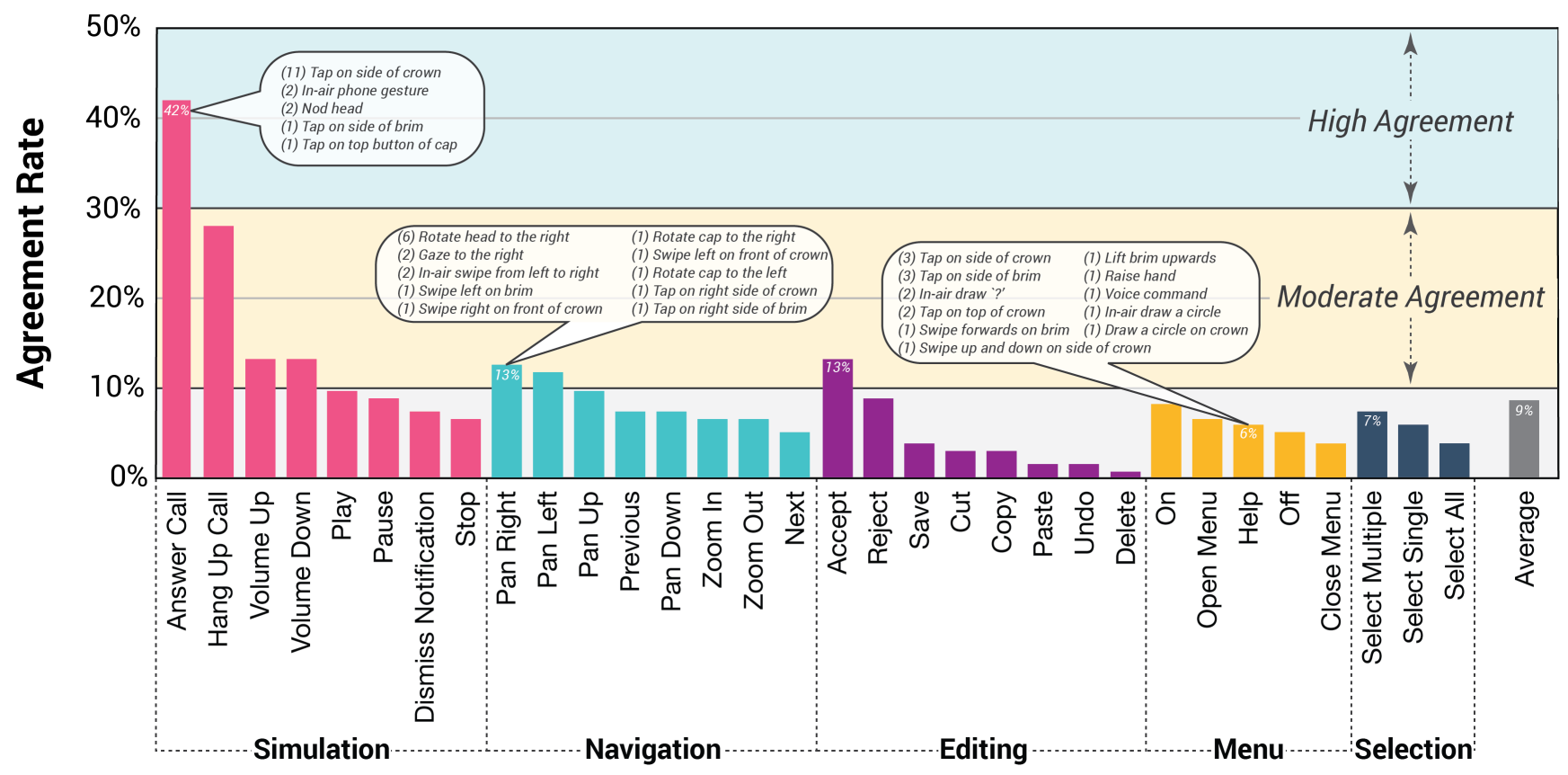

Figure 3. Agreement rates for the 32 referents, arranged by category. The complete set of elicited gestures for Answer Call, Pan Right, and Help are shown in the superimposed boxes; the number in parentheses is the number of participants that proposed a given gesture. Agreement rates of less than $10 \%$, between $10 \%$ and $30 \%$, and between $30 \%$ and $50 \%$ are considered low, moderate, and high agreement respectively [37].

Similar to prior gesture elicitation studies [4, 26, 28], we grouped gestures that were similar, rather than identical. Tapping the front of the crown with 1 finger was considered equivalent to performing the same gesture with 2, 3, or 4 fingers. Tapping once on the left side of the brim was considered equivalent to tapping twice or more. For gestures performed on a particular side (e.g., tap on the right side of the crown), we asked participants if the gesture had to be performed on that side, or if it was side independent. We factored this in to our results and analysis.

\section{Results}

We detail agreement rates for referents, define a consensus set for hat-based gestures, discuss participant preferences for input modalities, and report qualitative findings. Only participants' preferred gestures are included in our figures, results, and analysis. For reference, we list all participants preferred gesture proposals for the entire set of referents in Appendix A.

Agreement: We calculated agreement rates to quantify consensus between participants. The equation for calculating agreement rate is [37]:

$$
A R(r)=\frac{|P|}{|P|-1} \sum_{P_{i} \subseteq P}\left(\frac{\left|P_{i}\right|}{|P|}\right)^{2}-\frac{1}{|P|-1}
$$

where $P$ is the set of all proposals for referent $r,|P|$ the number of elicited proposals for that referent, and $P_{i}$ subsets of identical proposals from $P$ [37]. An agreement rate of 1.0 would indicate that every participant performed the exact same gesture; an agreement rate of 0.0 would indicate that every participant performed a unique gesture. We used the Agreement Analysis Toolkit (AGATe v2.0) to calculate our agreement rates [37].
Our agreement rates ranged from 0.01 (low agreement, $A R<0.10$ ) to 0.42 (high agreement, $0.30<A R<0.50$ ). The average agreement rate was 0.09 . As mentioned previously, we only considered preferred gestures in our analysis. The agreement rates of all referents can be found in Figure 3.

Consensus Set: For each referent, similar gestures were grouped together. The gesture with the largest consensus was chosen to be the consensus gesture for that referent. If at least 5 participants agreed on the consensus gesture, we included it within our consensus set (See Figure 5). With the exception of Reject $(A R=0.09)$, every gesture in our consensus set had moderate to high agreement.

\section{Emerging Themes}

Touch Gestures Preferred; Voice Gestures Avoided: Our results indicate that touch gestures are preferred over other input modalities. Out of the 544 preferred gestures in the initial condition (no constraints), 327 (60.1\%) were touch gestures. Two participants continued to prefer touch gestures in the Hands Dirty condition, opting to touch the hat with other parts of their body, such as their wrists and arms. Conversely, we

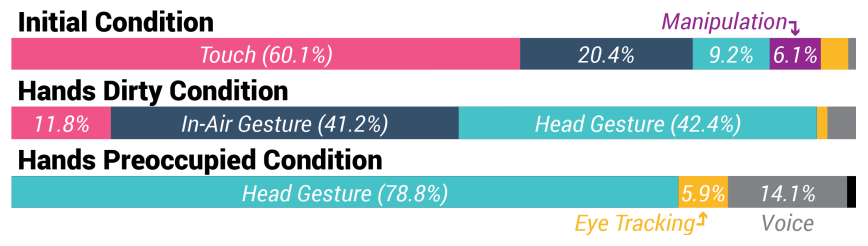

Figure 4. Classification of 544 preferred gestures in the initial condition (no constraints), 85 preferred gestures in the Hands Dirty condition, and 85 preferred gestures in the Hands Preoccupied condition. In the Hands Preoccupied condition, 1 participant proposed a neuromuscular sensing gesture (Tense Jaw), shown in black on the right. 


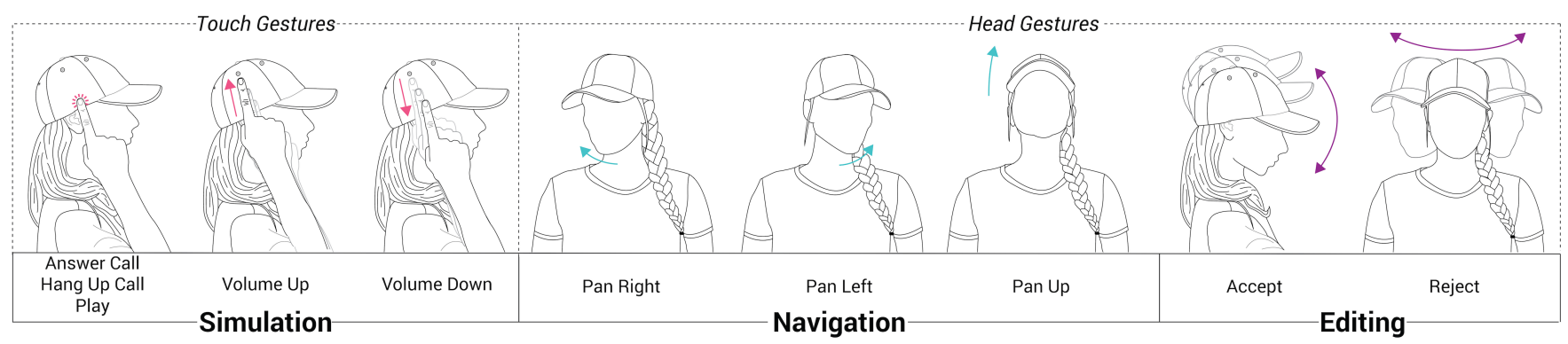

Figure 5. Consensus gesture set arranged by category and type of gesture.

found that participants seldom preferred voice gestures over other input modalities. Out of the 714 preferred gestures (from all conditions), only 21 were voice gestures (2.9\%). Only 1 participant opted for voice gestures in the initial condition (no constraints). Two other participants used voice gestures in the following conditions (hands dirty, hands preoccupied); however, this type of gesture was often seen as a last resort.

P6 I can't think of a good head gesture [for delete, so I would] say the word 'delete'.

In-Air Gestures Have Lower Agreement: While 111 preferred gestures in the initial condition (20.4\%) were in-air gestures, this modality had lower agreement. Despite an increase of in-air gestures in the Hands Dirty condition (41.2\% of preferred gestures), agreement rates did not rise similarly. For "Select All" under the Hands Dirty condition, the 17 participants converged on only 7 different gestures: 1 head gesture, 1 touch gesture, and 5 distinct in-air gestures. Whereas touch gestures are physically constrained by the form of the hat, head gestures are physically constrained by human anatomy, and manipulation gestures are constrained by a combination of the two, in-air gestures have a broader input space with less restrictions on potential inputs.

Constraints Increase Agreement: The Hands Dirty condition largely eliminated touch and manipulation gestures. The Hand Preoccupied condition eliminated touch, manipulation, and in-air gestures (See Figure 4 for a breakdown of gesture types across conditions). With fewer input modalities available, participants were more likely to agree on an appropriate gesture. In the Hands Dirty condition, 3 of 5 tasks had higher agreement than in the initial condition. In the Hands Preoccupied condition, all 5 referents had higher agreement than in the initial condition, all 5 referents had at least moderate agreement, and 1 task (Select All) had high agreement (See Figure 6). This suggests that limiting the space of potential inputs increases agreement. This is especially relevant for headwear associated with particular domains that require hands-free interaction (e.g., surgical caps, bicycle helmets).

Tangible Landmarks Can Inform Potential Touch Gestures: 22 preferred touch gestures in the initial condition (6.7\%) used features specific to the baseball cap such as the back strap, button, and eyelets. Participants who used these tangible landmarks were drawn to their tactile affordances.

P14 This feels like a button.

P7 It's such a tactile thing, it feels like [On/Off] should be there.

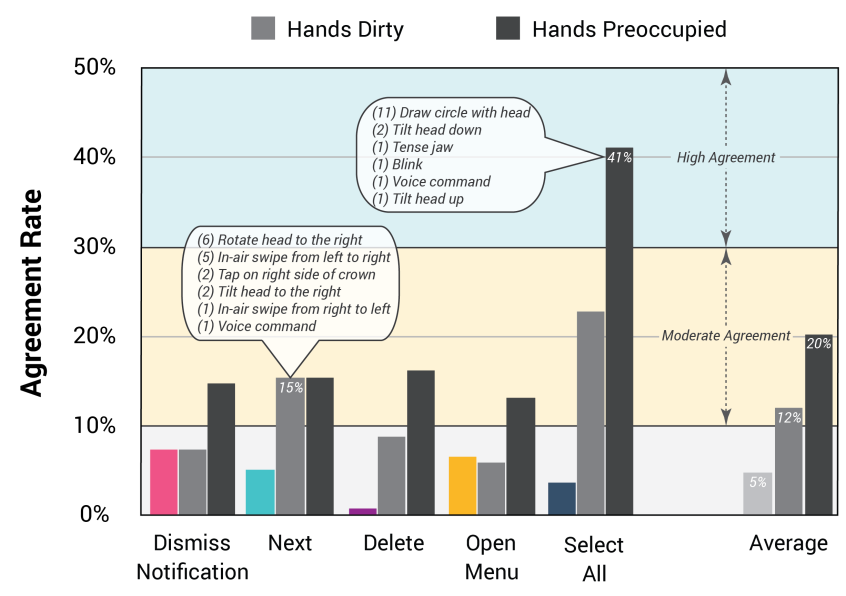

Figure 6. Agreement rates for the 5 referents repeated under 3 conditions: no constraints, hands dirty but mobile, and hands preoccupied and immobile.

Implications for Design

As illustrated in our consensus set (See Figure 5), gestures with the highest agreement were touch gestures on the crown and head gestures. While touch gestures had higher agreement, qualitative results indicate that participants are more interested in using a hat in situations where their hands are full or preoccupied. Thus, these interaction modalities should be prioritized similarly. From the 1,428 gestures performed during our elicitation study, we extracted a taxonomy of hat-based gestures (See Table 4). Although our taxonomy is informed by interactions with a baseball cap, the taxonomy can be tailored to other types of hats, particularly with regards to potential touch and manipulation gestures. The other modalities (Eye Tracking Gestures, In-Air Gestures, Head Gestures, and Voice Gestures) do not depend on the physical form of the hat, and thus can be applied to other types of hats without adjustment.

\section{DESIGN AND FABRICATION}

Informed by our elicitation study and design concerns, we designed and fabricated three hat prototypes capable of sensing touch and head gestures, and including ambient displays of several types. We implemented three separate prototypes to illustrate how the design concerns and taxonomy could be applied to distinct hats with varying physical affordances, associated contexts, and levels of formality. Our prototypes include a baseball cap, a fedora, and a flat cap (See Figure 7).

An Adafruit Feather 32u4 Bluefruit LE microcontroller is sewn into each hat. The battery is a rechargeable lithium ion 


\begin{tabular}{|c|c|c|}
\hline Class & \multicolumn{2}{|l|}{ Characteristics } \\
\hline \multirow{3}{*}{ Touch } & Location & $\begin{array}{l}\text { brim, crown, } \\
\text { button, strap, eyelet }\end{array}$ \\
\hline & Type of Gesture & tap, stroke, pinch, draw \\
\hline & Handedness & one handed, two handed \\
\hline \multirow{2}{*}{ Manipulation } & Type of Gesture & lift, pull, rotate \\
\hline & Handedness & one handed, two handed \\
\hline $\begin{array}{c}\text { Eye } \\
\text { Tracking }\end{array}$ & Point of Reference & hat, interface \\
\hline \multirow{3}{*}{ In-Air } & Point of Reference & head, body, interface \\
\hline & Type of Gesture & $\begin{array}{l}\text { wave, pose, swipe, } \\
\text { draw, pinch, point }\end{array}$ \\
\hline & Handedness & one handed, two handed \\
\hline $\begin{array}{l}\text { Head } \\
\text { Gesture }\end{array}$ & Type of Gesture & $\begin{array}{l}\text { rotate, tilt, move, } \\
\text { draw, gesture }\end{array}$ \\
\hline Voice & Mapping & direct, abstract \\
\hline
\end{tabular}

Table 4. Taxonomy of head-based gestures based on 1,428 collected gestures.

battery that is tucked into the facing of the crown for easy access. Our hat prototypes use Bluetooth LE to connect to external devices and displays and advertise their input and output capabilities over BLE using existing protocols ${ }^{6}$.

\section{Enabling Touch Interactions}

We implemented capacitive touch sensing on the sides of the crown using an Adafruit MPR121 Capacitive Touch Sensor and a grid of strips of conductive fabric. By detecting simultaneous changes in the capacitance of both horizontal and vertical strips of conductive fabric, we can detect the location of touch and characterize gestures such as swipes forwards, backwards, up, and down. While we could leverage past work to improve capacitive sensing techniques and capabilities [35, 29], our approach meets a key design concern: preserving the inherent functions of each hat type.

\section{Sensing Head Gestures}

We sense head gestures using an Adafruit BNO055 Absolute Orientation Sensor IMU. The IMU is embedded in the brim or sewn into the facing of the crown. We use simple thresholds to detect and classify 6 distinct head gestures: Rotate head to the left, Rotate head to the right, Tilt head up, Tilt head down, Nod head (up and down), Shake head (side to side). Incidentally, our implementation is also capable of detecting similar hat manipulations: Rotate hat to the left, Rotate hat to the right, Lift brim up, Pull brim down, Wiggle brim up and down, Wiggle brim side to side.

\section{Ambient Displays}

Unlike other clothing and accessories, hats are unique in that part of the hat (the brim) is always visible in the wearer's peripheral vision, whereas another part of the hat (the crown) is never visible to the wearer. Inspired by these physical affordances, we instrumented our hat prototypes with two visual ambient displays: one on the underside of the brim intended for the wearer to see, and one on the crown intended for others to see.

Personal Under-Brim Display. We instrumented the baseball cap and flat cap with RGB LEDs on the underside of the brim (See Figure 8 (Left) and Figure 1 (Middle)). The LEDs are angled such that they project light onto the entire underside

\footnotetext{
${ }^{6}$ https://www.bluetooth.com/specifications/gatt
}
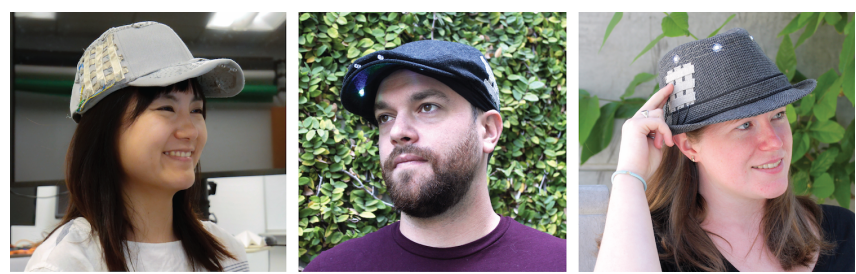

Figure 7. Three hat prototypes. Left: baseball cap prototype. Middle: flat cap prototype. Right: fedora prototype.

of the brim. The under-brim display can be used to provide feedback, indicating that a gesture has been correctly identified or communicating acknowledgments received from Bluetooth connected devices. This display is also capable of delivering ambient notifications in the user's peripheral vision, allowing them to continue their work without distraction and persisting in noisy environments. A smart surgical cap could notify a surgeon of patient biometrics without having to avert their gaze. A smart bicycle helmet could notify a cyclist of an upcoming detour without distracting them from the road. A concert-goer could receive text alerts on their hat, unable to feel the vibration of their phone over the vibration of the bass.

Public Crown Display. We integrated sewable NeoPixels into the eyelets of the baseball cap and across the crown of the fedora (See Figure 9). Following suggestions outlined in prior work [6], we opted for a display that is low fidelity, ambient, and ambiguous in nature. An external system could use the crown display to track the wearer through a smart environment. Additionally, crown displays could be used to communicate emotional state and interruptibility between coworkers.

\section{Leveraging the Physical Differences of Hats}

While all three of our hat prototypes incorporate both sensing modalities (touch and head gestures), ambient displays are implemented opportunistically and informed by the physical form of the hat. The baseball cap includes both ambient displays. The fedora has a shorter brim, so it does not include an under-brim display. The flat cap has a less structured crown, so it does not include a public crown display.

We implemented tangible landmarks where possible. Our elicitation study identified the button on top of the baseball cap's crown as the most prominent landmark (over the back strap, eyelets, and other features). Thus, we instrumented this feature of the hat with conductive fabric. We also worked to preserve the aesthetics and inherent functions of each hat. We have taken care to preserve the overall appearance of each of our hats, concealing electronics where possible.
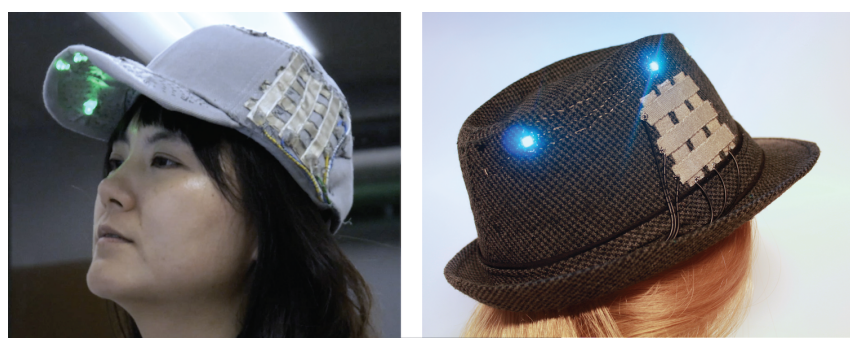

Figure 8. We designed and implemented two different classes of ambient displays. Left: personal under-brim display. Right: public crown display. 


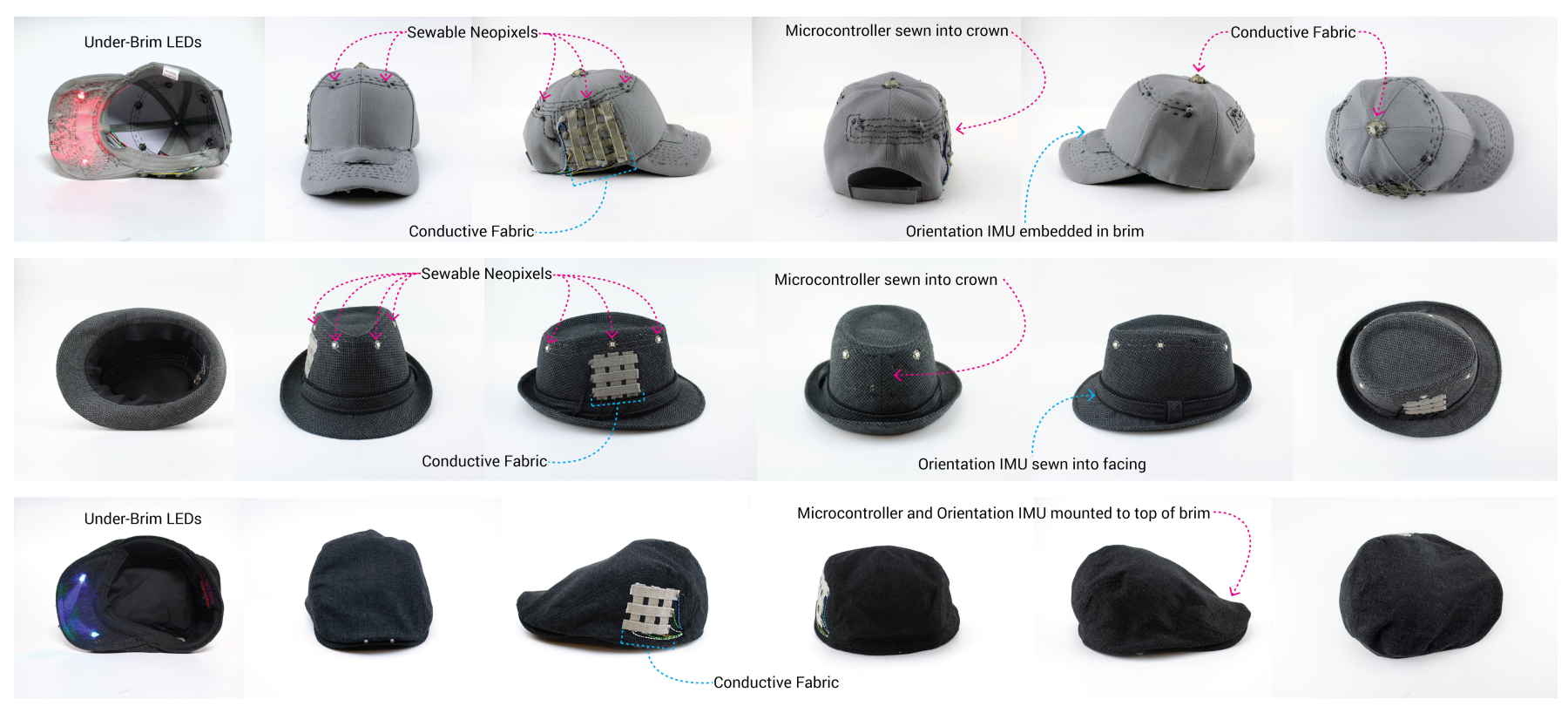

Figure 9. Hat prototypes capable of sensing touch and head gestures. The baseball cap (top) has ambient displays under the brim and across the crown; the fedora (middle) has an ambient display across the crown; and the flat cap (bottom) has an ambient display under the brim. In all three prototypes, the battery is tucked into the facing on the inside of the crown.

\section{PROTOTYPE EVALUATION}

We conducted an evaluation of our designed prototype and gestures obtained from our elicitation study. The evaluation had 10 users (5 male), none of which took part in the elicitation study. Users were recruited using email lists and word of mouth, and ranged in age from 21 to 55 (Mean $=37.7, \mathrm{SD}=$ 12.6). All users were right handed. The study had two parts: (1) Gesture Recognition, and (2) Task. All study procedures were video and audio recorded, transcribed, and analyzed.

1. Gesture Recognition: We first wanted to measure the accuracy of our sensing techniques. We instructed users to wear the hat prototype and demonstrated 8 gestures: Pan Left, Pan Right, Pan Up, Pan Down, Volume Up, Volume Down, Zoom In, Zoom Out. Five of these gestures are contained in our consensus set (See Figure 5); the other gestures were swiping forwards/backwards on the side of the crown (Zoom In/Out, respectively), and tilting the head down (Pan Down). We chose these gestures to evaluate both touch and head gestures, and to include gestures that had moderate agreement (Volume Up and Volume Down), as well as gestures with low agreement (Zoom In and Zoom Out). After we had demonstrated the gestures, users were prompted to perform each gesture 10 times in a row, for a total of 80 gestures.

2. Task: We then instructed users to complete a task using the hat as an interface (See Figure 1, right). Users were instructed to pan across an image to align crosshairs with 5 targets of differing sizes. Once inside each target, users were instructed to adjust the volume up or down. This task required panning in all four directions to find the targets, zooming to get the crosshairs completely inside the target, and adjusting the volume in both directions. The under brim LEDs flashed to indicate an acquired target.

Implementation: During Gesture Recognition, the hat communicated over BLE with a python script running on the re- searcher's laptop. For each recognized gesture, the hat sent the name (e.g., "Zoom Out") to the python script. The researcher closely tracked this log, recording how many gestures were recognized. During the Task, a modified version of the python script sent calls to the server hosting the task. The code running on the hat did not change between parts of the study.

\section{Results}

Accuracy: We observed significantly different accuracy for head gestures (Pan Left/Right/Up/Down) and touch gestures (Zoom In/Out, Volume Up/Down). The system achieved $100 \%$ accuracy for head gestures using a $15^{\circ}$ tolerance (rotating/tilting the head $15^{\circ}$ in any direction resulted in a panning gesture). The system achieved mean accuracy of $35.5 \%$ for touch gestures. Low accuracy for touch gestures can be attributed to a number of different factors: no training session, lack of calibration between users, absence of feedback, and insufficient indication of where to touch.

U6 I do not have very good spatial awareness of my gesture directions while touching my head.

During the task, the connected display provided visual feedback indicating whether or not gestures had been recognized. With this feedback, accuracy rates improved. Users took an average of 3 minutes 16 seconds to complete the task using the hat prototype (Max $=6$ minutes 30 seconds; Min $=1$ minute 50 seconds). While accuracy rates were low, they were sufficient for characterizing user thoughts and reactions to the hat prototype and associated gestures.

Perception of gestures: Users ranked each gesture on the same set of statements used in the initial elicitation study (See "Gesture Statements" in Table 2), allowing us to compare the thoughts and reactions of this set of users to the participants who initially suggested using such gestures. We found users to be biased by the recognition capabilities of our system. On 
all three statements, users in our second study ranked gestures with high accuracy rates (head movements - panning gestures) higher than the participants in our first study. Conversely, these users ranked gestures with low accuracy rates (touch gestures - volume up/down, zoom in/out) lower than the participants in our first study. This was true for all three gesture statements.

Perception of hat technology: Users also ranked the hat technology more generally using the same 4 statements from the first user study (See "Hat Statements" in Table 2). In both studies, these statements received middling ratings. One explanation for this emerged through our conversations with users; hat interfaces are desirable in specific contexts but not in general use. While no user imagined swapping out their Smartphone or mobile device for a hat, 8 out of 10 users imagined concrete situations in which they would use hat technology.

U10 It would be nice to use [hat technology] for navigation when you are doing outdoor activities such as hiking and jogging.

U6 [Hat technology] could be very useful for hospitals and restaurants. Scenarios where professionals wear hats for their daily work.

Users also imagined using hat-worn technology when biking (U4), controlling a television (U8), carrying something (U9), and "anytime when your hands are full and voice is not an option" (U3). Users were particularly drawn to the idea of "hands-free" interaction (U3, U5, U6, U8, U10).

Response to under-brim ambient display: While our user study mainly served to garner feedback on input modalities, we also elicited feedback on the under-brim display. When asked to rank how noticeable the display was on a 7-point Likert scale ( $1=$ Not noticeable, $7=$ Very noticeable), users gave it an average ranking of $5.2 \pm 1.7$, and responded positively to this display.

U3 The [under-brim display] could be useful even without the input elements. For example, if I want to know that a device was listening to me, or other notifications, these lights could be useful.

U6 The LED light gives me implicit feedback, which I like a lot compared to audio notifications. [It feels] less distracting.

\section{DISCUSSION}

Given the diversity of hat styles and contexts-of-use, our implementation barely scratches the surface. However, our design concerns and gesture taxonomy can be tailored to inform a variety of interactive hats. Factors to consider are physical form, inherent functions, and context of use.

Physical Form: The physical form of the hat influences the first three design concerns: how personal and public information is communicated, and potential tangible landmarks.

Brimless hats (e.g., yarmulkes, berets, kufi caps) do not lend themselves to under-brim displays or manipulation gestures, as there is not a natural place for users to grip and manipulate the hat. Bone conduction capabilities are largely unaffected by the physical form of the hat; however, as mentioned previously, vibration may prove effective for certain types of hats with loose-fitting features, such as lanyards, ear flaps, or tassels. Hats with structured crowns (e.g., top hats, fedoras, hardhats) are better substrates for crown displays than hats with flexible or non-existent crowns (e.g., flat caps, beanies, fascinators).
Hats also vary in terms of tangible landmarks. Hats may feature lanyards that secure underneath the chin (e.g., stetsons, fishing hats, party hats), eyelets or holes for ventilation (e.g., baseball caps, hardhats), decorative ribbons or bands (e.g., fedoras, stetsons), and logos/designs (e.g., baseball caps, beanies). This is just a small subset of potential tangible landmarks for hat technologies. Gesture taxonomies for hat interactions should be tailored with respect to these tangible landmarks; while other input modalities are largely unaffected by the form of the hat, potential touch and manipulation gestures largely depend on physical form.

Inherent Functions: Inherent functions of hats are a key design concern that should influence the design and fabrication of hat technologies. More formal hats (e.g., top hats) should prioritize subtle interaction capabilities and discreet technology. Hats worn explicitly for protection from the sun (e.g., sun hats) are less suited for visual displays that are less visible in direct sunlight.

Context-of-Use: Finally, associated contexts of hats can inform the technologies and capabilities that should be embedded in them. Hats typically worn outdoors (e.g., sun hats, baseball caps, fishing hats) are a natural substrate for light sensors and other measures of sun exposure. Hats associated with jobs (e.g., hardhats, hairnets) provide opportunities for networked interactions. Hats worn in noisy contexts (e.g., safety helmets, pilot/stewardess hats) should avoid using bone conduction so as to minimize the risk for cochlear damage.

\section{Limitations and Future Work}

While users in our prototype evaluation responded positively towards the hands-free capabilities and under-brim display, interactive hats should be evaluated in real-life contexts. Our study evaluated seated users interacting with an external display. Future work should examine a wider range of contexts including interactions with smartphones and IoT devices, as well as situations in which the user is standing, running, working, or doing a number of other activities. Finally, both of our studies were influenced by the culture in which they took place. All of our participants were educated adults in a Western society; our results are likely not generalizable across cultures. Further work is necessary to contextualize results across a broader society [19].

\section{CONCLUSION}

In this paper, we discussed factors relating to the design, fabrication, and evaluation of hat technologies. We hope that designers of future wearable technologies will leverage the physical affordances and widely accepted form factor of hats. We also hope that designers will interpret our work more broadly, considering how our approach can be applied to other under-explored form factors, further expanding the landscape of wearable technologies.

\section{ACKNOWLEDGEMENTS}

We thank Daniel Avrahami and John Doherty for their support, and Eric Paulos for guidance. We also thank our anonymous reviewers for their valuable feedback. 


\section{REFERENCES}

[1] Shaikh Shawon Arefin Shimon, Courtney Lutton, Zichun Xu, Sarah Morrison-Smith, Christina Boucher, and Jaime Ruiz. 2016. Exploring Non-touchscreen Gestures for Smartwatches. In Proceedings of the 2016 CHI Conference on Human Factors in Computing Systems (CHI '16). ACM, New York, NY, USA, 3822-3833. DOI :

http://dx.doi.org/10.1145/2858036.2858385

[2] Daniel Ashbrook, Patrick Baudisch, and Sean White. 2011. Nenya: Subtle and Eyes-free Mobile Input with a Magnetically-tracked Finger Ring. In Proceedings of the SIGCHI Conference on Human Factors in Computing Systems (CHI '11). ACM, New York, NY, USA, 2043-2046. DOI :

http://dx.doi.org/10.1145/1978942.1979238

[3] Jessica R. Cauchard, Jane L. E, Kevin Y. Zhai, and James A. Landay. 2015. Drone \&\#38; Me: An Exploration into Natural Human-drone Interaction. In Proceedings of the 2015 ACM International Joint Conference on Pervasive and Ubiquitous Computing (UbiComp '15). ACM, New York, NY, USA, 361-365. DOI: http://dx.doi.org/10.1145/2750858.2805823

[4] Edwin Chan, Teddy Seyed, Wolfgang Stuerzlinger, Xing-Dong Yang, and Frank Maurer. 2016. User Elicitation on Single-hand Microgestures. In Proceedings of the 2016 CHI Conference on Human Factors in Computing Systems (CHI '16). ACM, New York, NY, USA, 3403-3414. DOI : http://dx.doi .org/10.1145/2858036.2858589

[5] Beverly Chico. 2013. Hats and Headwear around the World: A Cultural Encyclopedia. ABC-CLIO.

[6] Laura Devendorf, Joanne Lo, Noura Howell, Jung Lin Lee, Nan-Wei Gong, M. Emre Karagozler, Shiho Fukuhara, Ivan Poupyrev, Eric Paulos, and Kimiko Ryokai. 2016. "I Don't Want to Wear a Screen": Probing Perceptions of and Possibilities for Dynamic Displays on Clothing. In Proceedings of the 2016 CHI Conference on Human Factors in Computing Systems (CHI '16). ACM, New York, NY, USA, 6028-6039. DOI : http://dx.doi .org/10.1145/2858036.2858192

[7] Christine Dierk, Molly Jane Pearce Nicholas, and Eric Paulos. 2018a. AlterWear: Battery-Free Wearable Displays for Opportunistic Interactions. In Proceedings of the 2018 CHI Conference on Human Factors in Computing Systems (CHI '18). ACM, New York, NY, USA, Article 220, 11 pages. DOI : http://dx.doi .org/10.1145/3173574.3173794

[8] Christine Dierk, Sarah Sterman, Molly Jane Pearce Nicholas, and Eric Paulos. 2018b. HäirIÖ: Human Hair As Interactive Material. In Proceedings of the Twelfth International Conference on Tangible, Embedded, and Embodied Interaction (TEI '18). ACM, New York, NY, USA, 148-157. DOI :

http://dx.doi.org/10.1145/3173225.3173232

[9] Noura Howell, Laura Devendorf, Rundong (Kevin) Tian, Tomás Vega Galvez, Nan-Wei Gong, Ivan Poupyrev,
Eric Paulos, and Kimiko Ryokai. 2016. Biosignals As Social Cues: Ambiguity and Emotional Interpretation in Social Displays of Skin Conductance. In Proceedings of the 2016 ACM Conference on Designing Interactive Systems (DIS '16). ACM, New York, NY, USA, 865-870. DOI :

http://dx.doi.org/10.1145/2901790.2901850

[10] Noura Howell, Laura Devendorf, Tomás Alfonso Vega Gálvez, Rundong Tian, and Kimiko Ryokai. 2018. Tensions of Data-Driven Reflection: A Case Study of Real-Time Emotional Biosensing. In Proceedings of the 2018 CHI Conference on Human Factors in Computing Systems (CHI '18). ACM, New York, NY, USA, Article 431, 13 pages. DOI :

http://dx.doi.org/10.1145/3173574.3174005

[11] Cindy Hsin-Liu Kao, Bichlien Nguyen, Asta Roseway, and Michael Dickey. 2017. EarthTones: Chemical Sensing Powders to Detect and Display Environmental Hazards Through Color Variation. In Proceedings of the 2017 CHI Conference Extended Abstracts on Human Factors in Computing Systems (CHI EA '17). ACM, New York, NY, USA, 872-883. DOI: http://dx.doi.org/10.1145/3027063.3052754

[12] Hsin-Liu (Cindy) Kao, Deborah Ajilo, Oksana Anilionyte, Artem Dementyev, Inrak Choi, Sean Follmer, and Chris Schmandt. 2017. Exploring Interactions and Perceptions of Kinetic Wearables. In Proceedings of the 2017 Conference on Designing Interactive Systems (DIS '17). ACM, New York, NY, USA, 391-396. DOI:

http://dx.doi.org/10.1145/3064663.3064686

[13] Hsin-Liu (Cindy) Kao, Manisha Mohan, Chris Schmandt, Joseph A. Paradiso, and Katia Vega. 2016. ChromoSkin: Towards Interactive Cosmetics Using Thermochromic Pigments. In Proceedings of the 2016 CHI Conference Extended Abstracts on Human Factors in Computing Systems (CHI EA '16). ACM, New York, NY, USA, 3703-3706. DOI: http://dx.doi .org/10.1145/2851581.2890270

[14] Arnav Kapur, Shreyas Kapur, and Pattie Maes. 2018. AlterEgo: A Personalized Wearable Silent Speech Interface. In 23rd International Conference on Intelligent User Interfaces (IUI '18). ACM, New York, NY, USA, 43-53. DOI :

http://dx . doi .org/10.1145/3172944.3172977

[15] KwanMyung Kim, Dongwoo Joo, and Kun-Pyo Lee. 2010. Wearable-object-based Interaction for a Mobile Audio Device. In CHI'10 Extended Abstracts on Human Factors in Computing Systems (CHI EA '10). ACM, New York, NY, USA, 3865-3870. DOI: http://dx.doi .org/10.1145/1753846.1754070

[16] Christian Kray, Daniel Nesbitt, John Dawson, and Michael Rohs. 2010. User-defined Gestures for Connecting Mobile Phones, Public Displays, and Tabletops. In Proceedings of the 12th International 
Conference on Human Computer Interaction with Mobile Devices and Services (MobileHCI'10). ACM, New York, NY, USA, 239-248. DOI :

http://dx.doi.org/10.1145/1851600.1851640

[17] Bing Li, Dawei Zheng, Yujia Lu, Fangtian Ying, and Cheng Yao. 2017. LightingHair Slice: Situated Personal Wearable Fashion Interaction System. In Proceedings of the 2017 CHI Conference Extended Abstracts on Human Factors in Computing Systems (CHI EA '17). ACM, New York, NY, USA, 1824-1828. DOI : http://dx.doi.org/10.1145/3027063.3053093

[18] Jennifer Mankoff, Anind K. Dey, Gary Hsieh, Julie Kientz, Scott Lederer, and Morgan Ames. 2003. Heuristic Evaluation of Ambient Displays. In Proceedings of the SIGCHI Conference on Human Factors in Computing Systems (CHI '03). ACM, New York, NY, USA, 169-176. DOI : http://dx.doi.org/10.1145/642611.642642

[19] Dan Mauney, Jonathan Howarth, Andrew Wirtanen, and Miranda Capra. 2010. Cultural Similarities and Differences in User-defined Gestures for Touchscreen User Interfaces. In CHI '10 Extended Abstracts on Human Factors in Computing Systems (CHI EA '10). ACM, New York, NY, USA, 4015-4020. DOI : http://dx.doi.org/10.1145/1753846.1754095

[20] Cameron S. Miner, Denise M. Chan, and Christopher Campbell. 2001. Digital Jewelry: Wearable Technology for Everyday Life. In CHI 'O1 Extended Abstracts on Human Factors in Computing Systems (CHI EA 'O1). ACM, New York, NY, USA, 45-46. DOI : http://dx.doi.org/10.1145/634067.634098

[21] Pranav Mistry and Pattie Maes. 2009. SixthSense: A Wearable Gestural Interface. In ACM SIGGRAPH ASIA 2009 Sketches (SIGGRAPH ASIA '09). ACM, New York, NY, USA, Article 11, 1 pages. DOI : http://dx.doi.org/10.1145/1667146.1667160

[22] Pranav Mistry, Pattie Maes, and Liyan Chang. 2009. WUW - Wear Ur World: A Wearable Gestural Interface. In CHI '09 Extended Abstracts on Human Factors in Computing Systems (CHI EA '09). ACM, New York, NY, USA, 4111-4116. DOI :

http://dx.doi.org/10.1145/1520340.1520626

[23] Meredith Ringel Morris, Andreea Danielescu, Steven Drucker, Danyel Fisher, Bongshin Lee, m. c. schraefel, and Jacob O. Wobbrock. 2014. Reducing Legacy Bias in Gesture Elicitation Studies. interactions 21, 3 (May 2014), 40-45. DOI : http://dx.doi.org/10.1145/2591689

[24] Don Norman. 2013. The design of everyday things: Revised and expanded edition. Constellation.

[25] Jennifer Pearson, Simon Robinson, and Matt Jones. 2015. It's About Time: Smartwatches As Public Displays. In Proceedings of the 33rd Annual ACM Conference on Human Factors in Computing Systems (CHI '15). ACM, New York, NY, USA, 1257-1266. DOI : http://dx.doi.org/10.1145/2702123.2702247
[26] Thammathip Piumsomboon, Adrian Clark, Mark Billinghurst, and Andy Cockburn. 2013. User-defined Gestures for Augmented Reality. In CHI '13 Extended Abstracts on Human Factors in Computing Systems (CHI EA '13). ACM, New York, NY, USA, 955-960. DOI : http://dx.doi .org/10.1145/2468356.2468527

[27] Halley Profita, Asta Roseway, and Mary Czerwinski. 2015. Lightwear: An Exploration in Wearable Light Therapy. In Proceedings of the Ninth International Conference on Tangible, Embedded, and Embodied Interaction (TEI '15). ACM, New York, NY, USA, 321-328. DOI :

http://dx.doi.org/10.1145/2677199.2680573

[28] Isabel Benavente Rodriguez and Nicolai Marquardt. 2017. Gesture Elicitation Study on How to Opt-in \& Opt-out from Interactions with Public Displays. In Proceedings of the 2017 ACM International Conference on Interactive Surfaces and Spaces (ISS '17). ACM, New York, NY, USA, 32-41. DOI : http://dx.doi.org/10.1145/3132272.3134118

[29] Munehiko Sato, Ivan Poupyrev, and Chris Harrison. 2012. Touché: Enhancing Touch Interaction on Humans, Screens, Liquids, and Everyday Objects. In Proceedings of the SIGCHI Conference on Human Factors in Computing Systems (CHI '12). ACM, New York, NY, USA, 483-492. DOI:

http://dx.doi.org/10.1145/2207676.2207743

[30] Eldon Schoop, James Smith, and Bjoern Hartmann. 2018. HindSight: Enhancing Spatial Awareness by Sonifying Detected Objects in Real-Time 360-Degree Video. In Proceedings of the 2018 CHI Conference on Human Factors in Computing Systems (CHI '18). ACM, New York, NY, USA, Article 143, 12 pages. DOI : http://dx.doi.org/10.1145/3173574.3173717

[31] Ted Selker, Andrea Lockerd, and Jorge Martinez. 2001. Eye-R, a Glasses-mounted Eye Motion Detection Interface. In CHI 'O1 Extended Abstracts on Human Factors in Computing Systems (CHI EA '01). ACM, New York, NY, USA, 179-180. DOI :

http://dx.doi.org/10.1145/634067.634176

[32] Teddy Seyed, Chris Burns, Mario Costa Sousa, Frank Maurer, and Anthony Tang. 2012. Eliciting Usable Gestures for Multi-display Environments. In Proceedings of the 2012 ACM International Conference on Interactive Tabletops and Surfaces (ITS '12). ACM, New York, NY, USA, 41-50. DOI :

http://dx.doi.org/10.1145/2396636.2396643

[33] Yulia Silina and Hamed Haddadi. 2015. New Directions in Jewelry: A Close Look at Emerging Trends \&\#38; Developments in Jewelry-like Wearable Devices. In Proceedings of the 2015 ACM International Symposium on Wearable Computers (ISWC '15). ACM, New York, NY, USA, 49-56. DOI : http://dx.doi.org/10.1145/2802083.2808410

[34] Sheridan Martin Small and Asta Roseway. 2011. The Printing Dress: You are what you Tweet. (2011). 
[35] Paul Strohmeier, Jarrod Knibbe, Sebastian Boring, and Kasper Hornbæk. 2018. zPatch: Hybrid Resistive/Capacitive eTextile Input. In Proceedings of the Twelfth International Conference on Tangible, Embedded, and Embodied Interaction (TEI'18). ACM, New York, NY, USA, 188-198. DOI : http://dx.doi.org/10.1145/3173225.3173242

[36] Ivan E. Sutherland. 1968. A Head-mounted Three Dimensional Display. In Proceedings of the December 9-11, 1968, Fall Joint Computer Conference, Part I (AFIPS '68 (Fall, part I)). ACM, New York, NY, USA, 757-764. DOI :

http://dx.doi.org/10.1145/1476589.1476686

[37] Radu-Daniel Vatavu and Jacob O. Wobbrock. 2015. Formalizing Agreement Analysis for Elicitation Studies: New Measures, Significance Test, and Toolkit. In Proceedings of the 33rd Annual ACM Conference on Human Factors in Computing Systems (CHI'15). ACM, New York, NY, USA, 1325-1334. DOI : http://dx.doi.org/10.1145/2702123.2702223

[38] Radu-Daniel Vatavu and Ionut-Alexandru Zaiti. 2014. Leap Gestures for TV: Insights from an Elicitation Study. In Proceedings of the ACM International Conference on Interactive Experiences for TV and Online Video (TVX '14). ACM, New York, NY, USA, 131-138. DOI: http://dx.doi.org/10.1145/2602299.2602316

[39] Katia Vega, Abel Arrieta, Felipe Esteves, and Hugo Fuks. 2014. FX e-Makeup for Muscle Based Interaction. In Design, User Experience, and Usability. User Experience Design for Everyday Life Applications and Services (DUXU '14). Springer, Berlin, Heidelberg, 643-652. DOI :

http://dx.doi.org/10.1007/978-3-319-07635-5_61
[40] Katia Vega, Marcio Cunha, and Hugo Fuks. 2015. Hairware: The Conscious Use of Unconscious Auto-contact Behaviors. In Proceedings of the 20th International Conference on Intelligent User Interfaces (IUI '15). ACM, New York, NY, USA, 78-86. DOI : http://dx.doi.org/10.1145/2678025.2701404

[41] Katia Fabiola Canepa Vega, Patricia J. Flanagan, and Hugo Fuks. 2013. Blinklifier: A Case Study for Prototyping Wearable Computers in Technology and Visual Arts. In Design, User Experience, and Usability. User Experience in Novel Technological Environments (DUXU '13). Springer, Berlin, Heidelberg, 439-445. DOI : http://dx.doi .org/10.1007/978-3-642-39238-2_4

[42] Wouter Walmink, Alan Chatham, and Florian Mueller. 2013. Lumahelm: An Interactive Helmet. In CHI'13 Extended Abstracts on Human Factors in Computing Systems (CHI EA '13). ACM, New York, NY, USA, 2847-2848. DOI :

http://dx.doi.org/10.1145/2468356.2479542

[43] Jacob O. Wobbrock, Meredith Ringel Morris, and Andrew D. Wilson. 2009. User-defined Gestures for Surface Computing. In Proceedings of the SIGCHI Conference on Human Factors in Computing Systems (CHI '09). ACM, New York, NY, USA, 1083-1092. DOI : http://dx.doi.org/10.1145/1518701.1518866

[44] Robert B Wood. 1992. Holographic head-up displays. Electro-optical displays (1992), 70-80.

[45] Shanhe Yi, Zhengrui Qin, Ed Novak, Yafeng Yint, and Qun Li. 2016. GlassGesture: Exploring head gesture interface of smart glasses. 2016 IEEE Conference on Computer Communications Workshops (INFOCOM WKSHPS) (2016). DOI :

http://dx. doi . org/10.1109/infcomw. 2016.7562233 


\section{APPENDIX A. COMPLETE SET OF GESTURE PROPOSALS}

We present the full list of preferred gestures proposed by our participants for all referents in our gesture elicitation study. Gestures suggested at least 3 times are highlighted in bold; gestures suggested at least 5 times are shown in bold pink.

\begin{tabular}{|c|c|c|}
\hline & Referent & coposed Gestures \\
\hline \multirow{8}{*}{ 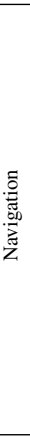 } & Previous & $\begin{array}{l}\text { Backwards swipe on side of crown, rotate head to the left, in-air swipe from right to left, tap on left side of crown, tap on left side of brim, tap on right side of crown, swipe left on brim, } \\
\text { backwards swipe on brim, swipe down on left side of crown, rotate cap to the right }\end{array}$ \\
\hline & Next & $\begin{array}{l}\text { Swipe forwards on brim, rotate head to the right, in-air swipe from left to right, tap on right side of crown, tap on right side of brim, swipe forwards on side of crown, backwards swipe } \\
\text { on right side of crown, swipe right on front of crown, swipe right on brim, swipe down on right side of crown, rotate cap to the left }\end{array}$ \\
\hline & Pan Left & $\begin{array}{l}\text { Rotate head to the left, gaze to the left, swipe right on brim, rotate cap to the left, in-air swipe from left to right, in-air swipe from right to left, swipe left on front of crown, rotate cap } \\
\text { to the right, tap on left side of crown, tap on left side of brim, swipe right on front of crown }\end{array}$ \\
\hline & Pan Right & $\begin{array}{l}\text { Rotate head to the right, gaze to the right, in-air swipe from left to right, swipe left on brim, rotate cap to the right, swipe right on front of crown, rotate cap to the left, tap on right side } \\
\text { of crown, tap on right side of brim, swipe left on front of crown }\end{array}$ \\
\hline & Pan Up & $\begin{array}{l}\text { Tilt head up, gaze up, in-air swipe down, swipe up on front of crown, backwards swipe on brim, in-air swipe up, lift brim upwards, swipe up on side of crown, tap on front of crown, tap } \\
\text { on center of brim }\end{array}$ \\
\hline & Pan Down & $\begin{array}{l}\text { Tilt head down, gaze down, in-air swipe up, swipe forwards on brim, swipe down on front of crown, pull brim downwards, in-air swipe down, swipe down on side of crown, tap on back } \\
\text { of crown, tap on center of brim }\end{array}$ \\
\hline & Zoom In & $\begin{array}{l}\text { Swipe forwards on side of crown, close pinch on crown, in-air open pinch, swipe forwards on brim, open pinch on brim, move head forward, in-air pinch and pull hand backwards, lift } \\
\text { cap off, in-air close pinch, tap on right side of brim }\end{array}$ \\
\hline & Zoom Out & $\begin{array}{l}\text { Swipe backwards on side of crown, open pinch on crown, in-air close pinch, swipe backwards on brim, close pinch on brim, move head backwards, in-air pinch and move hand } \\
\text { forward, rotate cap side to side, in-air open pinch, tap on left side of brim }\end{array}$ \\
\hline \multirow{8}{*}{ 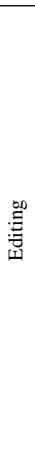 } & Cut & $\begin{array}{l}\text { In-air scissors gesture, in-air close pinch, tap on right side of brim, close pinch on brim, swipe forwards on left side of brim, swipe right on front of crown, swipe right on brim, diagonal } \\
\text { nod of the head, in-air diagonal swipe, in-air swipe down, lift cap off, wink, tap on side of brim }\end{array}$ \\
\hline & Copy & $\begin{array}{l}\text { Tap on side of crown, tap on side of brim, tap on front of crown, tap on top of crown, tap on center of brim, swipe forwards on right side of brim, swipe side to side on brim, nod head, } \\
\text { in-air place palms together and then lift top hand off the bottom hand, in-air pinch and pull hand back, in-air point at object, "Copy", lift cap off, blink }\end{array}$ \\
\hline & Paste & $\begin{array}{l}\text { Tap on center of brim, in-air open pinch, tap on side of brim, tap on side of crown, tap on top of crown, tap on front of crown, backwards swipe on right side of brim, swipe forwards on } \\
\text { right side of crown, tilt head up, rotate cap to the left, lift cap off, in-air place palms together and then slide the top hand off the bottom hand, in-air point at place to paste, in-air hold left } \\
\text { palm face up and then place right hand over left, blink }\end{array}$ \\
\hline & Delete & $\begin{array}{l}\text { In-air swipe from left to right, backwards swipe on left side of brim, swipe left on front of crown, swipe left on brim, swipe forwards on brim, tap on back of crown, draw an 'X' on } \\
\text { crown, in-air swipe from right to left, in-air close pinch, in-air open pinch, in-air wave, lift cap off, shake head, rotate head to the left, rotate cap } 360 \text { degrees on head, blink }\end{array}$ \\
\hline & Accept & Nod head, In-air thumbs up, tap on right side of crown, draw a circle on crown, draw a checkmark on crown, swipe right on brim, in-air "okay" gesture, rotate cap 360 degrees on head \\
\hline & Reject & $\begin{array}{l}\text { Shake head, draw an ' } X \text { ' on crown, tap on left side of crown, in-air thumbs down, in-air make an ' } X \text { ' with pointer fingers or arms, swipe left on brim, swipe left on front of crown, in-air } \\
\text { wave, lift cap off }\end{array}$ \\
\hline & Undo & $\begin{array}{l}\text { In-air draw circle, swipe left on brim, swipe left on front of crown, backwards swipe on left side of crown, swipe back and forth on side of crown, tap on back of crown, tap on left side } \\
\text { of crown, tap on left side of brim, tap on left side of brim then tap on right side of brim, tap on center of brim, shake head, rotate cap side to side, tilt head up, in-air extend hand and pull } \\
\text { back, in-air rotate wrist } 180 \text { degrees }\end{array}$ \\
\hline & Save & $\begin{array}{l}\text { Tap on top of crown, in-air swipe down, swipe down on side of crown, tap on side of crown, tap on side of brim, tap on back of crown, tap on front of crown, swipe up on front of crown, } \\
\text { in-air thumbs up, in-air close pinch, rotate cap } 180 \text { degrees on head, "Save" }\end{array}$ \\
\hline \multirow{8}{*}{ 竞 } & Answer Call & Tap on side of crown, in-air phone gesture, nod head, tap on side of brim, tap on top of crown \\
\hline & Hang Up Call & Tap on side of crown, in-air phone gesture, tap on back of crown, in-air swipe down, swipe down on side of crown, tap on side of brim, tap on top of crown \\
\hline & $\begin{array}{l}\text { Dismiss Noti- } \\
\text { fication }\end{array}$ & $\begin{array}{l}\text { Tap on side of crown, swipe right on brim, in-air swipe from left to right, in-air swipe up, swipe down on side of crown, swipe down on back of crown, swipe left on back of crown, } \\
\text { swipe backwards on side of crown, swipe up on front of crown, pull brim downwards, shake head }\end{array}$ \\
\hline & Volume Up & $\begin{array}{l}\text { Swipe up on side of crown, swipe forwards on side of crown, in-air swipe up, in-air rotate wrist clockwise, rotate cap to the right, swipe forwards on brim, swipe up on front of crown, } \\
\text { draw a clockwise circle on crown, tap on side of brim }\end{array}$ \\
\hline & $\begin{array}{l}\text { Volume } \\
\text { Down }\end{array}$ & $\begin{array}{l}\text { Swipe down on side of crown, swipe backwards on side of crown, in-air swipe down, in-air rotate wrist counter-clockwise, rotate cap to the left, swipe backwards on brim, swipe down } \\
\text { on front of crown, draw a counter-clockwise circle on crown, tap on top of crown }\end{array}$ \\
\hline & Play & $\begin{array}{l}\text { Tap on side of crown, tap on center of brim, tap on front of crown, swipe forwards on brim, tap on side of brim, tap on top of crown, swipe forwards on side of crown, in-air swipe down, } \\
\text { "Play", lift brim upwards }\end{array}$ \\
\hline & Pause & Tap on side of crown, tap on side of brim, tap on top of crown, tap on front of crown, tap on center of brim, in-air swipe down, swipe down on side of crown, "Pause", lift brim upwards \\
\hline & Stop & $\begin{array}{l}\text { Tap on side of crown, tap on side of brim, tap on top of crown, lift cap off, tap on center of brim, tap on front of crown, swipe up on front of crown, swipe down on side of crown, } \\
\text { backwards swipe on brim, in-air draw an 'S', "Stop" }\end{array}$ \\
\hline & Help & $\begin{array}{l}\text { Tap on side of crown, tap on side of brim, in-air draw a '?', tap on top of crown, swipe forwards on brim, draw a circle on crown, lift brim upwards, raise hand, "Help", swipe up and } \\
\text { down on side of crown, in-air draw a circle }\end{array}$ \\
\hline & Open Menu & $\begin{array}{l}\text { Tap on side of brim, tap on side of crown, swipe forwards on brim, open pinch on crown, lift brim upwards, in-air two hand gesture from center outwards, tap on back of crown, in-air } \\
\text { tapping gesture, in-air swipe up, gaze down, tap on top of crown }\end{array}$ \\
\hline & Close Menu & $\begin{array}{l}\text { Tap on side of brim, tap on side of crown, close pinch on crown, backwards swipe on brim, pull brim downwards, in-air two hand gesture from sides to center, tap on back of crown, } \\
\text { in-air draw an ' } \mathrm{X} \text { ', backwards swipe on side of crown, in-air swipe down, gaze up, tap on top of crown, swipe right on brim }\end{array}$ \\
\hline & On & $\begin{array}{l}\text { Tap on side of brim, tap on top of crown, in-air open pinch, tap on center of brim, in-air swipe down, lift brim upwards, swipe up on front of crown, in-air checkmark gesture (hand } \\
\text { pose), tap on side of crown, draw a circle on crown }\end{array}$ \\
\hline & Off & $\begin{array}{l}\text { Tap on top of crown, tap on side of brim, tap on center of brim, in-air open pinch, in-air swipe up, lift brim upwards, swipe down on front of crown, in-air thumbs down, in-air close } \\
\text { pinch, tap on side of crown, draw a circle on crown, tap on back of crown }\end{array}$ \\
\hline \multirow{3}{*}{ 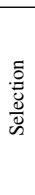 } & $\begin{array}{l}\text { Select Single } \\
\text { Item }\end{array}$ & $\begin{array}{l}\text { Look at object and tap on side of crown, look at object and tap on side of brim, point at object, tap on front of crown, backwards swipe on brim, gaze intently at object, in-air draw } \\
\text { a circle around object, in-air close pinch on object, look at object and blink, look at object and nod head, tap on area of crown that corresponds to the object }\end{array}$ \\
\hline & $\begin{array}{l}\text { Select Multi- } \\
\text { ple Items }\end{array}$ & $\begin{array}{l}\text { Look at object and tap on side of brim, point at objects, in-air draw a circle around objects, tap on area of crown that corresponds with object, backwards swipe on brim, look at each } \\
\text { object and nod head, look at each object and blink, swipe right on front of crown, tap on side of crown, multi-finger tap on brim (which fingers used corresponds to which objects to } \\
\text { select), hold brim with one hand and draw circles on the crown with the other to move the pointer and tap on the crown to select items }\end{array}$ \\
\hline & Select All & $\begin{array}{l}\text { Tap on both sides of brim, tap on top of crown, extend hand forwards, swipe right on brim, draw circle with head, in-air diagonal swipe, in-air swipe from left to right, lift cap off, in-air } \\
\text { draw rectangle, swipe right on front of crown, tap on side of crown, draw a circle on crown, press whole hand against brim }\end{array}$ \\
\hline \multirow{5}{*}{ 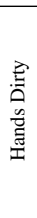 } & Next & Rotate head to the right, in-air swipe from left to right, tap on side of crown (with back of hand or arm), tilt head to the right, "Next", in-air swipe from right to left \\
\hline & $\begin{array}{l}\text { Dismiss Noti- } \\
\text { fication }\end{array}$ & $\begin{array}{l}\text { Shake head, In-air swipe from right to left, tilt head up, in-air backwards swipe, in-air swipe from left to right, in-air swipe down, in-air wave, in-air swipe up, tilt head to the left, } \\
\text { backwards swipe on side of crown (with back of hand or arm), swipe left or right on brim (with arm) }\end{array}$ \\
\hline & Delete & $\begin{array}{l}\text { Shake head, in-air backwards swipe, in-air swipe from left to right, rotate head to the left, in-air swipe from right to left, in-air wave, in-air open pinch, tap on side of crown (with back } \\
\text { of hand), tap on side of brim (with arm), in-air close pinch, "Delete" }\end{array}$ \\
\hline & Open Menu & $\begin{array}{l}\text { Tilt head up, nod head, in-air two hand swipe from center outwards, in-air backwards swipe, extend hand forwards, in-air swipe up, gaze down, tap on front of crown (with back of hand } \\
\text { or arm), open pinch on crown (with wrists), snap fingers, tilt head down, "Alexa" }\end{array}$ \\
\hline & Select All & Draw circle with head, in-air close pinch, tap on top of crown (with arm), extend hand forwards, in-air diagonal swipe, in-air swipe from left to right, in-air draw a rectangle \\
\hline \multirow{5}{*}{ 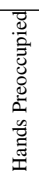 } & Next & Rotate head to the right, tilt head to the right, "Next", gaze to the right \\
\hline & $\begin{array}{l}\text { Dismiss Noti- } \\
\text { fication }\end{array}$ & Shake head, tilt head down, tilt head up, "Dismiss", rotate head to the left, gaze up, tilt head to the left \\
\hline & Delete & Shake head, tilt head down, rotate head to the left, "Delete", tilt head up then right then down then left, tilt head to the left \\
\hline & Open Menu & Tilt head up, tilt head down, voice command ("Open Menu" or "Alexa"), nod head, draw circle with head, gaze intently, gaze down \\
\hline & Select All & aw circle with head, tilt head down, tense jaw, blink, "Select All", tilt head up \\
\hline
\end{tabular}

